\title{
Demographic and health surveillance of mobile pastoralists in Chad: integration of biometric fingerprint identification into a geographical information system
}

\author{
Daniel Weibel ${ }^{1}$, Esther Schelling ${ }^{1}$, Bassirou Bonfoh ${ }^{2}$, Jürg Utzinger ${ }^{1}$, Jan Hattendorf ${ }^{1}$, \\ Mahamat Abdoulaye ${ }^{3}$, Toguina Madjiade ${ }^{3}$, Jakob Zinsstag ${ }^{1}$ \\ ${ }^{1}$ Department of Public Health and Epidemiology, Swiss Tropical Institute, P.O. Box, CH-4002 Basel, \\ Switzerland; ${ }^{2}$ Centre Suisse de Recherches Scientifiques, B.P. 1303, Abidjan 01, Côte d'Ivoire; ${ }^{3}$ Centre de \\ Support en Santé International, B.P. 972, N’Djamena, Chad
}

\begin{abstract}
There is a pressing need for baseline demographic and health-related data to plan, implement and evaluate health interventions in developing countries, and to monitor progress towards international development goals. However, mobile pastoralists, i.e. people who depend on a livestock production system and follow their herds as they move, remain marginalized from rural development plans and interventions. The fact that mobile people are hard to reach and stay in contact with is a plausible reason why they are underrepresented in national censuses and/or alternative sequential sample survey systems. We present a proof-of-concept of monitoring highly mobile, pastoral people by recording demographic and health-related data from 933 women and 2020 children and establishing a biometric identification system (BIS) based on the registration and identification of digital fingerprints. Although only 22 women, representing $2.4 \%$ of the total registered women, were encountered twice in the four survey rounds, the approach implemented is shown to be feasible. The BIS described here is linked to a geographical information system to facilitate the creation of the first health and demographic surveillance system in a mobile, pastoralist setting. Our ultimate goal is to implement and monitor interventions with the "one health" concept, thus integrating and improving human, animal and ecosystem health.
\end{abstract}

Keywords: biometric fingerprint, biometric identification system, demographic surveillance, geographical information system, nomadic pastoralists, mobile livestock production system, Chad.

\section{Introduction}

The United Nation's (UN) Universal Declaration of Human Rights, put forth in 1948, stipulates an identity to every individual. However, the political rhetoric of human rights, and the academic discourse of entitlements, functioning and capabilities remain elusive for the global poor. Indeed, most legal and civil rights declared in constitutions and

Corresponding author:

Daniel Weibel

Department of Public Health and Epidemiology

Swiss Tropical Institute, P.O. Box, CH-4002 Basel, Switzerland

Tel. +41 61284 8286; Fax +41612848105

E-mail: daniel.weibel@unibas.ch the social service provisions granted by states to their citizens are largely inaccessible to unregistered or otherwise legally non-existent individuals. Additionally, the maintenance of civil registration systems stagnated in many developing countries over the past 30 years, and hence the rights proclaimed by the UN remain in-executable. Recently, Setel et al. (2007) described the connection between development and the human right of registration and conjectured that several of the millennium development goals (MDGs) rely on accurate data for fertility, mortality and causes of deaths.

Sequential sample survey systems are increasingly established as an alternative to national censuses. For example the demographic surveillance systems 
(DSS) within the INDEPTH network generate mortality and fertility rate estimates to monitor population dynamics over time. But there remains the concern about equity and representativeness of sample survey systems. For example, the non-representation of certain population strata in these systems and national censuses is due to a lack of reliable information about mobile pastoralists related to demography, health, and socioeconomic issues. To remedy this, cross-sectional sampling methods have been proposed for nomadic groups. Although the "water-point approach" seemed to be feasible when applied in two rural zones of Somalia, there were a number of logistical difficulties (Kalsbeek, 1986). Another approach that has been used to obtain population data on mobile communities in areas with a low population density is aerial censuring with two independent observers on board an airplane recording tents, people and livestock herds in randomly selected, geographical sectors. However, considering that not all individuals are equally good at sighting, this sampling approach requires a correction factor taking into account lack of visibility, which must be cross-validated with field-based studies. A capturemark-recapture methodology is applied by population ecologists to obtain estimates on the demography of open and migratory populations. Epidemiologists have primarily used capture-recapture to estimate the degree of undercount in surveillance systems. Although this latter approach has been proposed for population-size estimates of Sudanese nomads by Elgoul (1978) some 30 years ago, it has not been applied to date.

The generation of a unique identity through biometric registration is central for longitudinal surveys and censuses and could assist overcoming underrepresentation of mobile populations in national surveys which has the potential of contributing to the establishment of a DSS for mobile pastoralists. Fingerprint identification dates back more than 100 years and its implications in medical and legal inquiries are well acknowledged. Public awareness of biometrics has increased, which is partially explained by a number of large-scale projects, e.g. travel entry procedures such as the US-VISIT programme (U.S. Department of Homeland Security). The three most prominent technologies in biometrics at present are fingerprint, facial and iris recognition. Iris and fingerprint recognition have high accuracy rates and are useful in matching biometric templates in large databases, while facial recognition is particularly user-friendly explaining why a number of existing databases already use facial images for identification (Anonymous, 2005). In many fields, research in fingerprint technology and biometrics is advancing and the accuracy and efficiency has been enhanced, as reviewed recently by Yun and Cho (2006). de Luis-Garcia et al. (2003) have provided an overview of the key features of biometric identification, together with a description of the main biometric technologies currently in use. By assessment of characteristics of types of biometric features (fingerprint, hand geometry, voice, retina, iris, signature and face), based on different quality parameters, the fingerprint technology holds particular promise with regard to accuracy and ease of implementation, whereas costs are ranked as intermediate.

Since 2000, the Chadian veterinary services and the expanded programme of immunization (EPI) of the World Health Organization (WHO), together with the Swiss Tropical Institute (STI) in Switzerland and the Centre de Support en Santé International (CSSI) in Chad, are conducting joint human and animal vaccination campaigns for mobile pastoralists in the Lake Chad area. Based on observations of negligible coverage rates of the EPI among children and women, preventive measures were implemented (Schelling, 2002; Wiese, 2004; Schelling et al., 2005, 2007). However, the evaluation of vaccination programmes for children (against BCG, measles, yellow-fever, poliomyelitis, diphtheria, whooping cough and tetanus), and for women (against tetanus), faces considerable challenges to generate reliable baseline demographic data with regard to mobile communities. The project described here was launched for surveillance of demographic and health-related information of 
mobile pastoralists to show whether or not the vaccination campaigns are having their desired effect on mortality in the Lake Chad area. The main objective, however, was to explore the feasibility of biometric fingerprint registration and the integration of a biometric information system (BIS) into a geographical information system (GIS) for demographic and health surveillance of mobile pastoralists. It is felt that such a surveillance system would not only help to evaluate the joint human and animal vaccination campaigns but also deepen our understanding of health, social and economic issues with regard to the resource-based vulnerability of mobile pastoralists and their dependence on the mobile livestock production system.

This study has been guided by a concrete BIS application within an evaluation design of a smallscale vaccination programme among pastoralist communities. Pastoral women and their children were registered by biometric fingerprint technology and monitored with a BIS. Biometric registration does not register a child at birth, but children can be tracked as their information is attached to the biometric identification of their mothers.

\section{Materials and methods}

\section{Study area}

The study was carried out at the southern shores of Lake Chad in Chari-Baguirmi, which is located in the semi-arid Sahelian belt south of the Sahara desert. It is bordered in the west by the Chari River and its interior delta which empties into Lake Chad and in the north by the lake shores. Overall, a surface area of $4,275 \mathrm{~km}^{2}$ was covered, with a northsouth extension of $45 \mathrm{~km}$ and a west-east extension of $95 \mathrm{~km}$. The study zone covers the area of the vaccination campaigns, jointly conducted by STI and CSSI from 2000 to 2007 in the intervention zone of "Gredaya".

Rainfalls are limited to a short rainy season from July to September with the occurrence of years of drought resulting in an internally patchy, scattered and variable availability of pastoral resources (water and pastures).

The coastal floodplains of Lake Chad consist of islands, swampy areas, pools and arms of the lake covering a zone of approximately $10 \mathrm{~km}$ from the water body to the south followed by a sandy and shrubby area for another $35 \mathrm{~km}$.

\section{Study population}

In the dry season nomadic communities of Arab, Fulani and Gorane ethnic groups concentrate in the Lake Chad region. Communities of all three ethnic groups in the Lake Chad region are mainly cattle breeders but also keep small ruminants. Arab and Fulani groups stay close to the shores or some Fulani families occupy islands at the end of the rainy season before cultivated fields block access to the waterbody. Most Fulani also have agricultural fields (Schelling, 2002). Goranes are well acquainted with constructing deep wells that allow them to stay further away from the shores and using dryer pastures. When the first rains occur all groups leave the southern Lake Chad area to move east and north to feed their animals on fresh pastures. Year after year the pastoralists undertake movements over several hundred kilometres between rainy and dry season pastures. Our study was done during the dry season when mainly short movements occur. Such movements are due to grazed pasture or dried-out ponds, expired access rights and nuisance due to insects. Individuals encountered in July and in November were likely to be leaving or entering the zone for their macro-movements. Further details on migration patterns, household socioeconomics and sociocultural relationships are provided elsewhere (Wiese, 2004).

The most recent Chadian census dates back to 1993. At that time, there were approximately 83,500 nomads among an estimated rural population of 900,000 in the Chari-Baguirmi and Kanem districts of Chad (Ministère du Plan et de la Coopération et al., 1995). It is conceivable that the number of nomads has been underestimated consid- 
erably because during the census period in April, several nomadic groups were located across the border in the neighbouring countries of Cameroon, Niger, and Nigeria.

Our study population, the target population of the joint human and animal vaccination programme (Schelling et al., 2007) in the intervention zone of "Gredaya", comprised the main ethnic groups of Arab, Fulani and Gorane mobile livestock keepers. In randomly selected camps (the selection of camps is described below) we sampled all women at reproductive age who were present during our survey, including their children if younger than 12 years. The joint human and animal vaccination campaigns commenced in 2000 among mobile pastoralist communities at Lake Chad and children under the age of 5 years were targeted. Hence, the youngest were born in 2000 and the oldest in 1995. As the vaccination campaigns were implemented until 2007 (Abdoulaye et al., 2006; Schelling et al., 2007), we sampled in 2007 all children born between 1995 and 2007, so the eldest children sampled were 12-year-olds.

\section{Ethical considerations}

The Chadian Ministry of Health $(\mathrm{MoH})$ and the Ethics Committees of the State and University of Basel (EKBB) in Switzerland approved this study, including the collection, storage and analysis of biometric data. For privacy reasons, all fingerprintrelated information, demographic and health data and geographical coordinates were stored in three separate databases and were only linked for final analysis via unique identification numbers. All private information was treated confidentially.

\section{Applied biometric tools}

Biometrics is the science of identifying people using physiological features. BIS can operate in two different ways: verification (or authentication) and identification. Verification compares a personal identification number (PIN) to the biometric feature stored in a database. For identification, a BIS com- pares biometric features in the database that will identify an individual among all enrolled (de LuisGarcia et al., 2003). For convenience and rapidity, most BIS seek identification rather than verification (Mesec, 2007). In the present study, the focus was on identification.

In the field (Fig. 1) we used an IBM notebook (International Business Machines Corp.; New York, USA) and a fingerprint scanner W32 (Microsoft Corp.; Redmond, USA) as hardware. We used version 1.0.2 of the Desktop Identity software (Griaule Biometrics Corp.; San Jose, USA) for fingerprint registration and identification. For database management, we used Microsoft Access 2002 (Microsoft Corp.; Redmond, USA). Electricity was assured by two Sunbag L (Off-Grid Systems Ltd.; Zillis, Switzerland) solar panels with storage batteries and a portable fuel generator (Yamaha Corp.; Hamamatsu, Japan). Geographical coordinates were collected with a hand-held global positioning system (GPS) Geko 201 (Garmin Ltd., Olathe, USA). Demographic, health and GPS data were transferred as attributes to a GIS using ArcGIS 9 ArcMap 9.1 (ESRI, Redlands, USA) software for spatial data management and mapping.

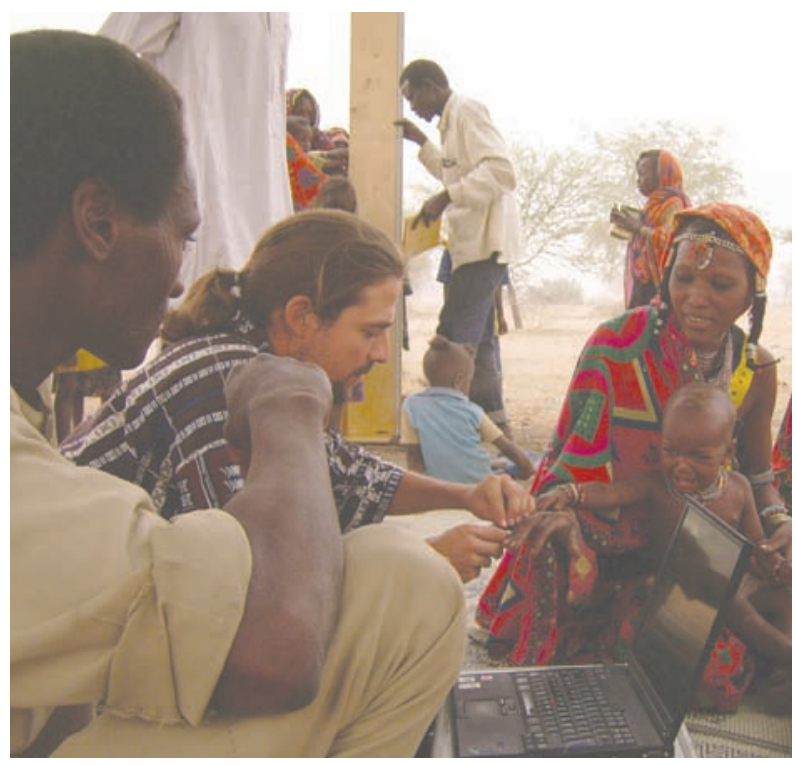

Fig. 1. Biometric registration of a Fulani woman south of Lake Chad (Foto M. Béchir, 2007). 


\section{Sampling and analysis}

During four survey rounds of approximately two weeks each, carried out in March, April/May, July/August and November 2007, a fingerprint scanner was used under field conditions. One survey round consisted of several transects and randomly selected areas where transects could not be performed. Random transects could only be performed in the sandy and shrubby study zones whereas the coastal zone was covered by a random selection of areas based on a list of accessible areas by car. Starting points and directions for transects were chosen by drawing of lots. There were lots with all the directions (N, NE, E, SE, S, SW, NW) and numbered lots $(10,20,30, \ldots, 100)$. The reference point was the village Gredaya (geographical coordinates: $12^{\circ} 57^{\prime} 28.40$ " longitude, $15^{\circ} 3$ '51.55" latitude). The number indicated the distance from Gredaya in a drawn direction where the transect should start. In these random transects visible nomadic camps (feriks) were approached. Average visibility was $\sim 1$ $\mathrm{km}$ depending on weather conditions (e.g. dust and sand in the air) and vegetation.

At arrival of our team in a ferik we were always received by an adult or adolescent male to whom we presented the objective and the content of the study. To obtain informed consent, according to the prevailing tradition, most often elder men were consulted but not women. All available women older than 12 years were asked to present their vaccination cards if they had been vaccinated and their fingerprints were scanned using the thump of the right hand and the little finger of the left hand for registration and identification. Demographic and health data from the women and their children aged below 12 years were recorded. The data collection was organized in a two-step procedure; registration, followed by identification. Once an individual is registered, this individual can be readily identified again if encountered at a later survey round. This identification procedure allows that health and demographic data are constantly up-dated, using the unique fingerprint identification number as the key identifier.
Relevant data obtained at registration and reencountering (e.g. geographical coordinates and date of the encounter) of individuals were recorded. Information was collected by interviewing the mothers with a pre-tested questionnaire asking for the following data: name, year of birth, ethnic group, vaccination status (doses, provider, date of last vaccination), name of husband, number of children lost in a lifetime (retrospective child mortality), age when child died and self-reported cause of death, and number of children alive at time of the interview, including name, sex, age, date of death if deceased between survey rounds and vaccination status.

Health and demographic data from children were linked to the fingerprint key identifier of their mother or the woman caring for a child to avoid scanning and recognition problems of fingerprints from children which might become distorted to some degree due to growth.

\section{Results}

Figure 2 shows the study area in the south-coastal zone of Lake Chad and the transects of the four survey rounds along which nomadic pastoralists were identified and interviewed in 2007. Overall, in the four survey rounds 104 camps were visited and fingerprints were registered from 933 women who could be linked to 2,020 children aged between 1 day and 12 years (Table 1 ). Only 22 women, representing $2.4 \%$ of the total registered women, were encountered twice. The mean number of children younger than 12 years of age per woman varied from 1.5 in the first to 2.5 in the third survey round.

Figure 3 shows all surveyed feriks in the year 2007 (depicted by points). Gorane people were encountered in each of the survey rounds in the southern part of our study area. The costal zone of the floodplains of Lake Chad is seasonally populated by Fulani and Arabs, whereas no Gorane people were encountered there. Fulani and Arab families move away from the lake into dryer areas southeast. During the fourth survey round in November 2007 we observed that Fulani communities were 


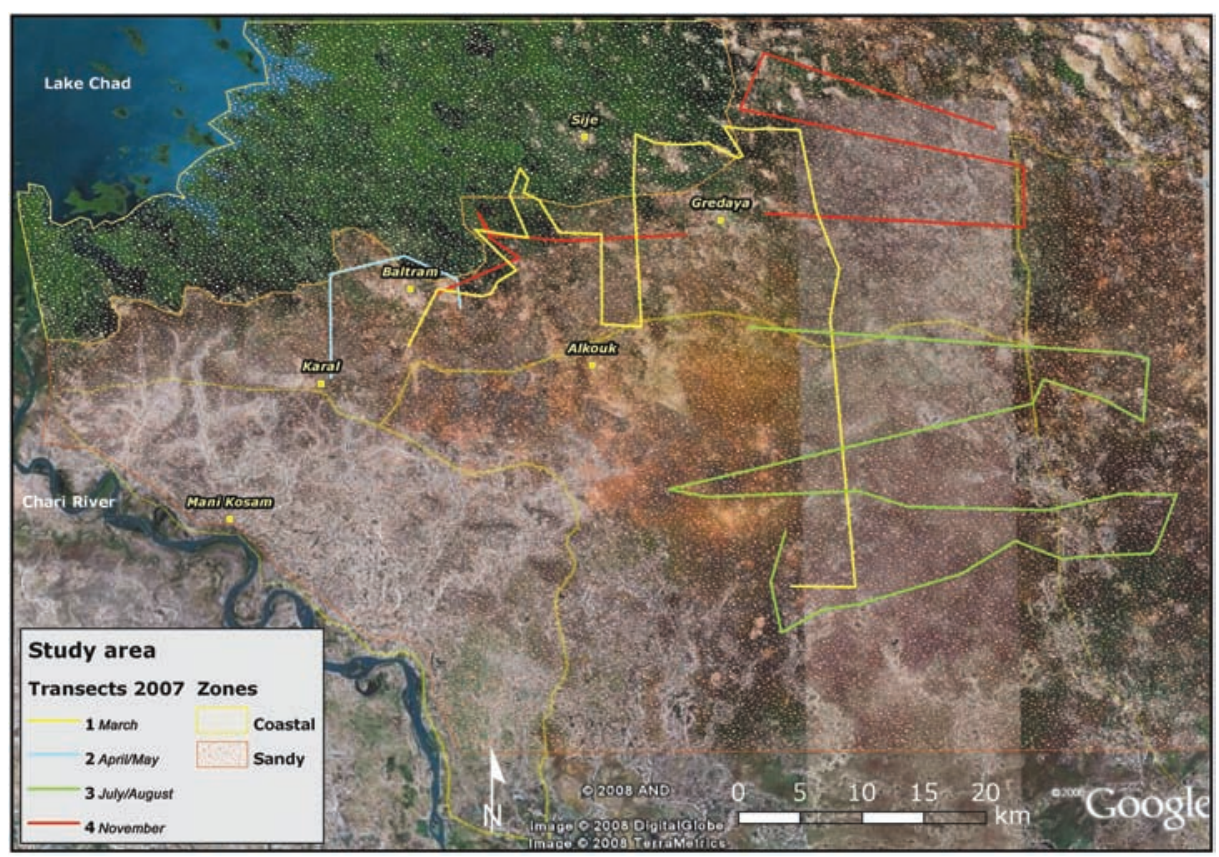

Fig. 2. Study area south of Lake Chad and the transects of the 4 survey rounds where nomadic pastoralists were identified and interviewed in 2007 (Background: Google Earth 2008).

Table 1. Registered and re-encountered mobile pastoralist mothers and their children in four survey rounds in 2007 in the study area south of Lake Chad.

\begin{tabular}{|c|c|c|c|c|c|c|c|}
\hline \multirow{2}{*}{ Round } & \multirow{2}{*}{$\begin{array}{l}\text { Dates in } \\
2007\end{array}$} & \multicolumn{3}{|c|}{ No. of individuals registered } & \multicolumn{3}{|c|}{ No. of individuals re-encountered } \\
\hline & & Women & Children & Mean $^{1}$ & Women & Children & Mean $^{1}$ \\
\hline 1 & $15 / 3-27 / 3$ & 196 & 295 & 1.5 & 0 & 0 & - \\
\hline 2 & $23 / 4-15 / 5$ & 342 & 761 & 2.2 & 0 & 0 & - \\
\hline 3 & $25 / 7-2 / 8$ & 225 & 567 & 2.5 & 20 & 36 & 1.8 \\
\hline 4 & $18 / 11-30 / 11$ & 170 & 397 & 2.3 & 2 & 2 & 1 \\
\hline TOTAL & & 933 & 2,020 & 2.2 & 22 & 38 & 1.7 \\
\hline
\end{tabular}

${ }^{1}$ Children per woman

using the coastal zone, whereas Arabs were not found in that location at that time.

Fulani and Arab women encountered twice had left the shores of Lake Chad after the survey round in April/May and were re-encountered 20-30 km (aerial line) south-east three months later (Fig. 4). The two Gorane women registered twice first seen in March 2007 moved $30 \mathrm{~km}$ to the east where we met them again in the July/August 2007 survey.

The biometric fingerprint registration and identification among nomadic people was feasible although we encountered problems in scanning the fingerprints of 94 women which corresponds to $10.1 \%$ of all encountered women. The workload of women older than 25 years was visible in their hands: they had scratches and callus and thus their fingerprint images were of low quality. In other cases, the fingerprint light scanner had problems to scan fingers covered with "henna", the widely used make-up of all three ethnical groups. The yelloworange-brown henna Fulani used interfered less with the scanner than the dark brown-black henna of Arab and Gorane women. Cleaning of the scanner surface and the participants fingertips with 


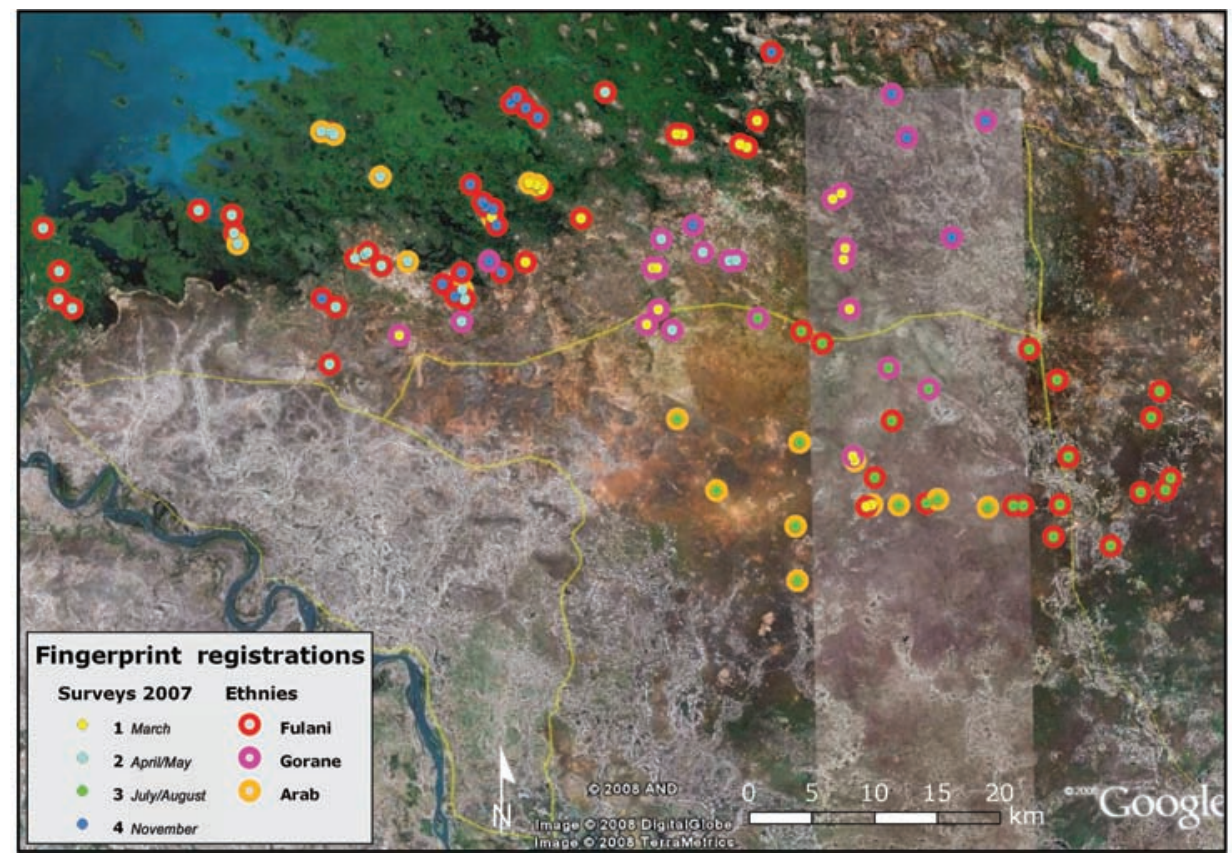

Fig. 3. Study area south of Lake Chad and sampled mobile pastoralist feriks in the year 2007 (depicted by points) and main ethnicity of the people encountered (outer ring around the points). The colours of the points represent the four transects when women of childbearing age and their children were registered or re-encountered. The outer ring around the points shows the main ethnicity of the people encountered (Background: Google Earth 2008).

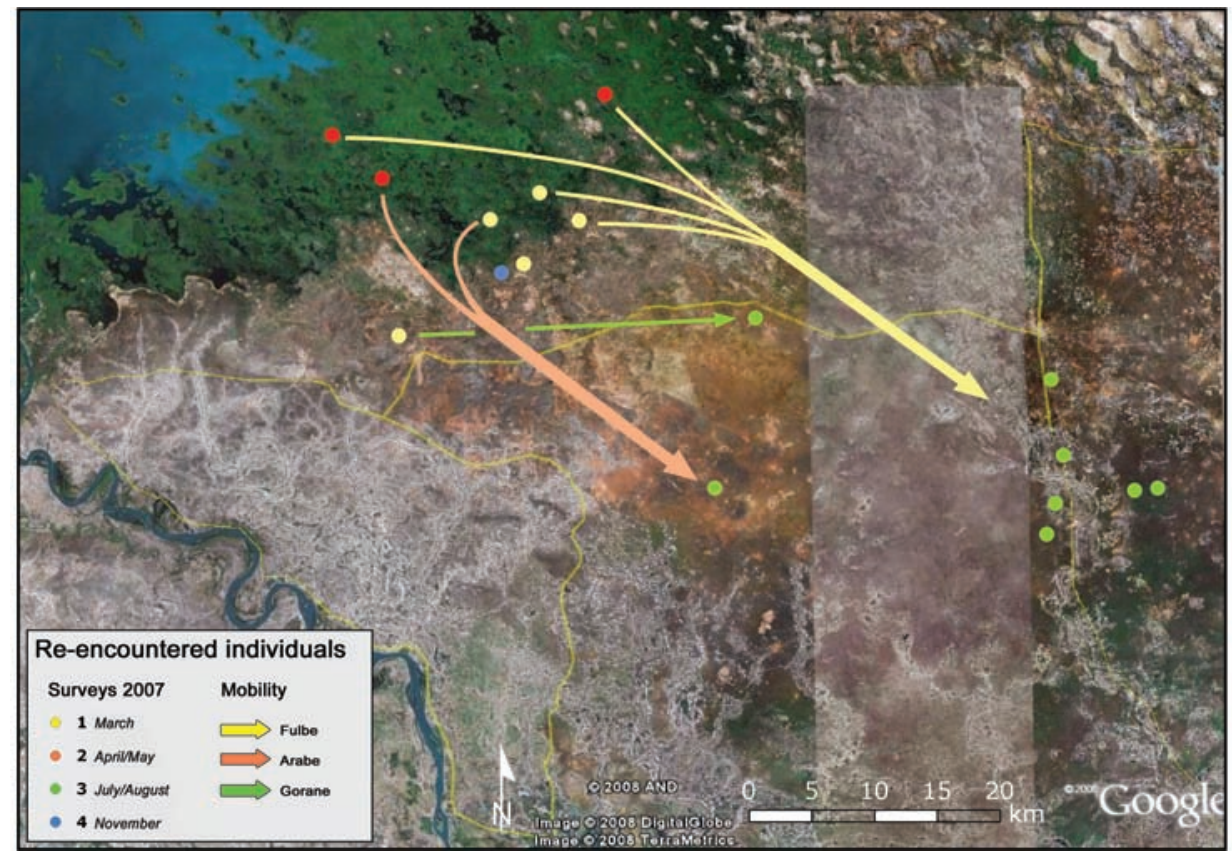

Fig. 4. Study area south of Lake Chad and 22 mobile pastoralist women who were encountered twice in different survey rounds including arrows indicating their likely movement over time. Information is shown for the different ethnic groups (Background: Google Earth 2008). 
ethanol aided in the reading of fingerprints. In 94 cases we failed to obtain a satisfying image, even from the little finger of the left hand, and hence we registered these individuals according to their name, the name of the husband and the chiefs' name.

In addition to the solar panels, we used a portable fuel generator to supply the notebook and the scanner, because cloudiness (e.g. in March during the season of Harmattan winds) and heat (in April, when temperatures went up to $53^{\circ} \mathrm{C}$ in the shadow) inhibited the optimal functioning of the panels and batteries.

Figure 5 shows how the BIS was integrated into a GIS, which can be used for subsequent epidemiological and population modelling approaches that should facilitate the integration into a health and demographic surveillance system (HDSS) for a mobile population.

\section{Discussion}

In the Sahelian semi-arid belt at the southern border of the Sahara desert, extensive mobile livestock production systems prevail. Over the past 10,000 years, mobile livestock production and the nomadic way of life have evolved under these semi-arid climatic conditions with seasonal rainfalls and periodic draughts. Due to adaptation of the production system, extensive mobile livestock production is seen as perhaps the most sustainable natural resource management strategy to use scarce and remote semi-arid rangelands (Niamir-Fuller, 1999). However, sustainable development taking into account the rapid economic, environmental and sociopolitical changes may be difficult to achieve because mobile populations live in remote areas where they are hard to reach for surveys and interventions. The provision of social interventions and services such as health and education for pastoralists and the other $40 \%$ of the Chadian rural population living far $(>15 \mathrm{~km})$ from the nearest health facility (Ouagadjio et al., 1998) remains a challenge. New strategies are needed to provide adapted, integrated and sustainable social services for mobile pastoralists that protect and foster their sustainable livestock production systems (Bonfoh et al., 2007). Changes in the demographic composition and social organization (also due to settlement to access social services) play a crucial role in sustainable use of resources, thus demographic

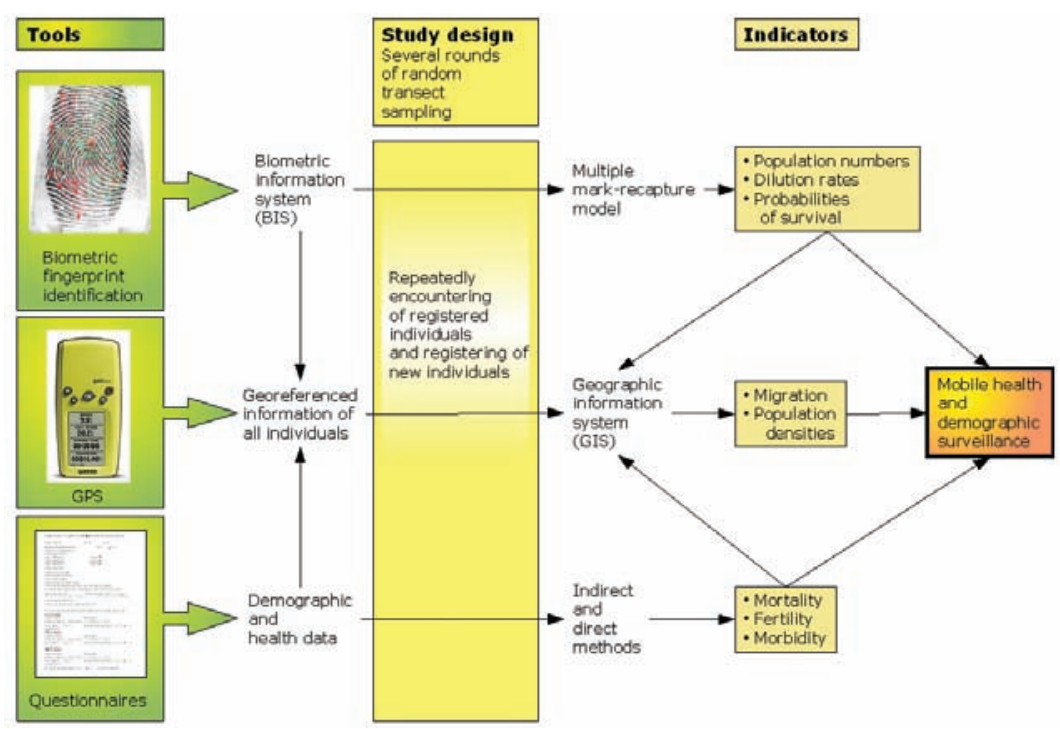

Fig. 5. Suggested conceptual framework for the combination of BIS and GIS together with epidemiological and population modelling approaches towards the integration into a HDSS for mobile pastoralists. 
parameters are key indicators for the monitoring of MDGs and for appraisal of whether social, environmental and economic development is truly sustainable (Goodland, 1995).

We have shown that the registration of vital data is feasible in highly mobile pastoral settings with the proof-of-concept and the methods of biometric fingerprint registration and identification. We see an opportunity in the combination of biometric identification and GIS to be an integrated tool for a HDSS among mobile people. Such a HDSS could provide an extended platform for the monitoring of extensive livestock production system parameters such as livestock population, productivity and pasture and water resource management. It may therefore contribute to monitor both sustainable natural resource management and progress in sustainable development. Since health of mobile pastoralists is the result of complex interactions between health systems, the economy of livestock production systems, sociocultural background, sustainable resource management, environmental health and political powers, broader approaches such as a "one health" approach are needed.

\section{Feasibility of a HDSS for mobile people}

Due to heavy rains in August 2007, the third survey round was shortened from 13 to 9 days. In the second round, we achieved higher registration numbers probably because we stayed somewhat longer in the field. On average we sampled 14-15 women per day. The number of sampled women was directly linked to their availability during day time. It was exceedingly difficult to sample women when they were busy to fulfil their daily tasks. Their workload depended on available help from children (preparing meals, milking animals, care giving for other children, going to markets to sell milk and buy crop, collect water for the family, collecting firewood, etc.). We found that the morning time after breakfast from 8 am to noon was most suitable. Another important factor influencing the number of sampled women per ferik was how soon husbands were found and how long it took to explain the purpose of the study and to obtain informed consent. Given the cultural norm with male chaperones, we could hardly establish informed "face to face" consent with the women. We assume that only women with mutual consent presented themselves. We observed women staying away. The number of sampled women per day was further affected if random transects led into unpopulated zones due to degraded pasture (e.g. thornbush vegetation and burnt surface areas).

The illustrated assumed direction of migration as a line between the GPS coordinate of registration and re-encountering in Figure 3 has to be seen in a wider pattern of seasonal migration of mobile pastoralists, where Gorane and Fulani would move more east-westwards and Arab ethnic groups northeast-south-westwards depending on their livestock composition. It is important to note that we only encountered $2.4 \%$ of the 933 registered women twice in different survey rounds. This issue raises some concern about aspects of the feasibility of the study which is discussed in the next section.

\section{Methodological and equipment challenges}

The intermixing of the population due to microand macro-movements and the conducted random transects visualized a scattered population over time and space. Random transects represent a mobile survey method compared to a fixed householdbased demographic survey. Obstacles in the field such as dense vegetation, crop fields, and inlets from the lake as well as burned areas often prevented us to follow the selected transect up to the border of the study area. In principle, a transect should have crossed the whole study area, but as they were directed off course by the obstacles this led to a few uncompleted ones.

Visibility was highly influenced by factors such as weather conditions and vegetation. At the end of the rainy season (November) gramineous species grew up to $2.5 \mathrm{~m}$ high and in March there was much sand and dust in the air due to the Harmattan winds from the north. 
Since growth of fingers could influence the recognition of the fingerprint, we assigned the children's data to the identification of their mother. When children were not together with their mothers but in the care of another household (for example their grandparents), we assigned the data of the child to the woman of the household of care.

We saw that among 472 vaccinated women 59\% had lost their vaccination card. Therefore, a centralized health care provider database combined with patient records and vaccination cards at the household-level could help to reduce loss of health information.

High losses of patient records of the nomadic people together with the difficulty to identify a nomadic individual by name, date and place of birth and social relationship led us to evaluate the usefulness of fingerprint technology. This biometric tool provides an individual identification number in the health database, where all patient records are managed. This health database contains relevant demographic information on births and deaths, together with spatial georeferenced information that can be managed in a GIS. But these quantitative data have to be interpreted with the contribution of qualitative observations. Randall (2004) promotes greater variety of data collection methods and increased triangulation in demography combining quantitative and qualitative approaches. Watkins and Fleisher (2002) draw on experiences in the Somali National Regional State of Ethiopia in the establishment of a migrant tracking system and trace out the main components of such a system. They argue that any method for collecting and interpreting information on migratory patterns must be combined with an analysis of ethnic identity, group structure, and indigenous knowledge systems and, therefore, requires interdisciplinary approaches. Based on findings from five populations in Sahelian central Mali surveyed in 1981/1982, Hill (1985) concluded that broad generalization on the demography and the extrapolation of data from one to other mobile populations is inappropriate. Biometric fin- gerprint recognition could be an interesting identification tool for ethnological and social research to generate health and demographic evidence among mobile people. In the health system, biometric technology was mainly introduced in hospitals to identify patients and to link health information (diagnosis, drug distribution and disease history) as recently described in a study carried out in Malawi (Yu et al., 2005). There are few reports where fingerprint technology was used in the field of epidemiology and clinical trials. In a phase II cholera vaccine trial in Vietnam the authors used fingerprint technology for the identification of trial participants (The Sonla Research Group, 2007). Continued work towards the integration of fingerprint technology in a HDSS placing more emphasis on biometric registration and identification of mobile pastoralists using fingerprints as individual markers, is under way in the form of a multiple mark-recapture study to estimate population sizes, in and out migration and survival rates of the same population at the Lake Chad area.

Observed good acceptance in our study (we hardly had any refusal for participation) was based on the trust mobile pastoral communities have established during the joint human and animal vaccination programme to the service providers (Schelling et al., 2007). It might be more difficult to obtain consent for fingerprinting from a pastoralist population that has not been reached by (health-) service provision.

\section{Conclusion}

Lack of monitoring and inadequate information systems are important hindering factors to plan, implement and sustain social services in remote rural zones. The biometric registration provides an unique identification number to an individual where the name, place and date of birth alone cannot identify people. In a survey of static households, identification is easier when compared to mobile households because interviewers can rely to a certain degree on re-finding the same persons in the same 
households combined with the use of geographical information on the location of the household. Biometric registration is a methodological improvement towards permanent individual "marking" for mark-recapture for estimation of population sizes, migratory dilution rates and survival and other demographic parameters such as mortality and fertility rates. The combination of biometrics and GIS could be an adequate instrument to foster new "notfixed-household-based-methods" for studies where individuals have to be recognized and re-found individually. The use of biometric registration and identification among mobile pastoralists could contribute to the creation of a HDSS in highly mobile pastoralist settings and thus address some of the outstanding issues in surveying nomadic communities for census and health issues. This would provide vital and health-related data of marginalized populations. New interventions and services could be planned and implemented and ongoing actions could be evaluated and improved towards equityeffectiveness. For example, longer vaccination rounds in shifting vaccination zones due to changing pastures situations could better be planned to reduce drop-out rates and improve vaccination coverage. In a system's perspective, a HDSS could be extended towards the monitoring of mobile livestock production systems taking into account sustainable pastoral resource management and livestock health using the "one health" approach.

The implication of biometric tools and their combination with GIS in demography and epidemiology among mobile people are being developed and need to be validated at a larger scale. Next to analyses of cost-effectiveness, legal and ethical issues of biometric data acquisition and management have to be part of a complete validation process before biometric tools become potentially applicable towards a HDSS in highly mobile populations.

This study tested the use of biometric fingerprint recognition tools and found the approach to be a good way to minimize problematic issues of registration and proper identification in subsequent samplings and surveys among mobile people.

\section{Acknowledgments}

The research for this paper was carried out within the Transversal Package Project "Pastoral Production System" of the Swiss National Centre of Competence in Research (NCCR) North-South: Research Partnerships for Mitigating Syndromes of Global Change, co-funded by the Swiss National Science Foundation (SNF) and the Swiss Agency for Development and Cooperation (SDC).

We thank Prof. M. Tanner, director of STI, Dr. D.M. Daugla, director of CSSI, the Freie Akademische Gesellschaft Basel (FAG), the Stiftung Emilia Guggenheim-Schnurr, the Chadian authorities and the nomadic communities for their support to this study.

\section{References}

Abdoulaye MA, Schelling E, Bechir M, Daugla D, Madjiade T, Zinsstag J, Weibel D, Bonfoh B, 2006. Vaccination: les enfants et les mères, mais aussi leurs animaux! Bull Med Mundi Schweiz 102, 40-43 (http://www.medicusmundi.ch/ mms/services/bulletin/bulletin200604/kap2/102sti.html).

Anonymous, 2005. 2004 market review. Biomed Technol Today 13, 9-11.

Bonfoh B, Zinsstag J, Munch A, Fokou G, Weibel D, Ould TM, Bechir M, Tanner M, 2007. New approaches in health and social services provision for nomadic people in the Sahel. Boeree MJ (Ed). 5th European Congress on Tropical Medicine and International Health (May 24-28, Bologna, Italy). Medimond, Amsterdam, The Netherlands, 223-229.

de Luis-Garcia R, Alberola-Lopez C, Aghzout O, Ruiz-Alzola J, 2003. Biometric identification systems. Signal Processing $83,2539-2557$.

Elgoul AE, 1978. The estimation of human population by the capture-recapture method. Monograph Series No. 5. Khartoum. Faculty of Economic and Social Studies, University of Khartoum. Development Studies and Research Centre.

Goodland R, 1995. The concept of environmental sustainability. Ann Rev Ecol Syst 26, 1-24.

Hill AG, 1985. Population, health and nutrition in the Sahel: issues in the welfare of selected West African communities. Routledge and Kegan Paul, London, UK, 351 pp.

Kalsbeek WD, 1986. Nomad sampling: an analytic study of 
alternative design strategies. Am Stat Assoc, 169 pp.

Mesec C, 2007. Fingerprint identification versus verification. Biomed Technol Today 15, 7.

Ministère du Plan et de la Coopération, Ministère de l'Intérieur et de la Sécurité, 1995. Recensement général de la population et de l'habitat 1993. N’Djaména, Tchad. Le Ministère, Chad.

Niamir-Fuller M, 1999. Managing mobility in African rangelands: the legitimization of transhumance. Food and Agriculture Organization of the United Nations (FAO), London, UK.

Ouagadjio B, Nodjimadji K, Ngoniri JN, Ngakoutou N, Ignégongba K, Tokindang JS, 1998. Enquête démographique et de santé, Tchad 1996-1997. Calverton (MD), Bureau Central du Recensement et Macro.

Randall S, 2004. Qualitative data in demography: the sound of silence and other problems. Demogr Res 11, 57-94.

Schelling E, 2002. Human and animal health in nomadic pastoralist communities of Chad: zoonoses morbidity and health services. PhD Thesis, Swiss Tropical Institute, University of Basel, Switzerland, 184 pp.

Schelling E, Bechir M, Ahmed MA, Wyss K, Randolph TF, Zinsstag J, 2007. Human and animal vaccination delivery to remote nomadic families, Chad. Emerg Infect Dis 13,
373-379.

Schelling E, Daoud S, Daugla DM, Diallo P, Tanner M, Zinsstag J, 2005. Morbidity and nutrition patterns of three nomadic pastoralist communities of Chad. Acta Trop 95, 16-25.

Setel PW, Macfarlane SB, Szreter S, Mikkelsen L, Jha P, Stout S, Abouzahr C, 2007. A scandal of invisibility: making everyone count by counting everyone. Lancet 370, 15691577.

The Sonla Research Group, 2007. Using a fingerprint recognition system in a vaccine trial to avoid misclassification. Bull World Health Organ 85, 64-67.

Watkins B, Fleisher ML, 2002. Tracking pastoralist migration: lesson from the Ethiopian Somali national regional state. Hum Organ 61, 328-338.

Wiese M, 2004. Health-vulnerability in a complex crisis situation. Verlag für Entwicklungspolitik. Saarbrücken, Germany, 436 pp.

Yu KL, Chen CC, Chang WS, Juma H, Chang CS, 2005. Fingerprint identification of AIDS patients on ART. Lancet 365, 1466.

Yun EK, Cho SB, 2006. Adaptive fingerprint image enhancement with fingerprint image quality analysis. Imag Vis Comput 24, 101-110. 